\title{
New tools for scientific learning in the EduSeis project: the e-learning experiment
}

\author{
Antonella Bobbio $\left({ }^{1}\right)$, Luciana Cantore $\left({ }^{2}\right)$, Nicola Miranda $\left({ }^{3}\right)$ and Aldo Zollo $\left({ }^{2}\right)$ \\ (1) Istituto Nazionale di Geofisica e Vulcanologia, Osservatorio Vesuviano, Sezione Napoli, Italy \\ (') Dipartimento di Scienze Fisiche, Università degli Studi di Napoli «Federico II», Napoli, Italy \\ ${ }^{(3)}$ ITIS «E. Majorana», Somma Vesuviana, Napoli, Italy
}

\begin{abstract}
The Educational Seismological Project (EduSeis) is a scientific and educational project, the main aim of which is the development and implementation of new teaching methodologies in Earth Sciences, using seismology as a vehicle for scientific learning and awareness of earthquake risk. Within this framework, we have recently been experimenting with new learning and information approaches that are mainly aimed at a high school audience. In particular, we have designed, implemented and tested a model of an e-learning environment in a high school located in the surroundings of the Mt. Vesuvius volcano. The proposed e-learning model is built on the EduSeis concepts and educational materials (web-oriented), and is based on computer-supported collaborative learning. Ten teachers from different disciplines and fifty students at the ITIS «Majorana» technical high school (Naples) have been taking part in a cooperative e-learning experiment in which the students have been working in small groups (communities). The learning process is assisted and supervised by the teachers. The evaluation of the results from this cooperative e-learning experiment has provided useful insights into the content and didactic value of the EduSeis modules and activities. The use of network utilities and the «Learning Community» approach promoted the exchange of ideas and expertises between students and teachers and allowed a new approach to the seismology teaching through a multidisciplinary study.
\end{abstract}

Key words e-learning - Jigsaw method - EduSeis web tools

\section{Introduction}

The Educational Seismological Project (EduSeis) is a research and experimentation project that is aimed at involving research centres, universities, scientific museums and schools in the consolidation and maintenance of a prototype of

Mailing address: Dr. Antonella Bobbio, Istituto Nazionale di Geofisica e Vulcanologia, Osservatorio Vesuviano, Sezione Napoli, Via Coroglio 156, 80124 Napoli, Italy; e-mail: bobbio@na.infn.it a seismographic network that is formed of high technology and low cost components (Bobbio and Zollo, 2000). The project is designed to promote the Earth Sciences (especially Seismology and Geophysics) and an to increase awareness of seismic risk at the level of high schools and the public at large through the «Città della Scienza» Science Centre in Naples. A network of digital seismographs has been installed in a number of high schools in Central and Southern Italy (Cantore et al., 2003). Through the continuous updating of seismic data, and following its analysis and processing, relevant events are selected and made available on the EduSeis website (http:// eduseis.na.infn.it) (fig. 1).

The project has many educational, scientific and social goals. The main educational objectives are to train students and teachers in the 


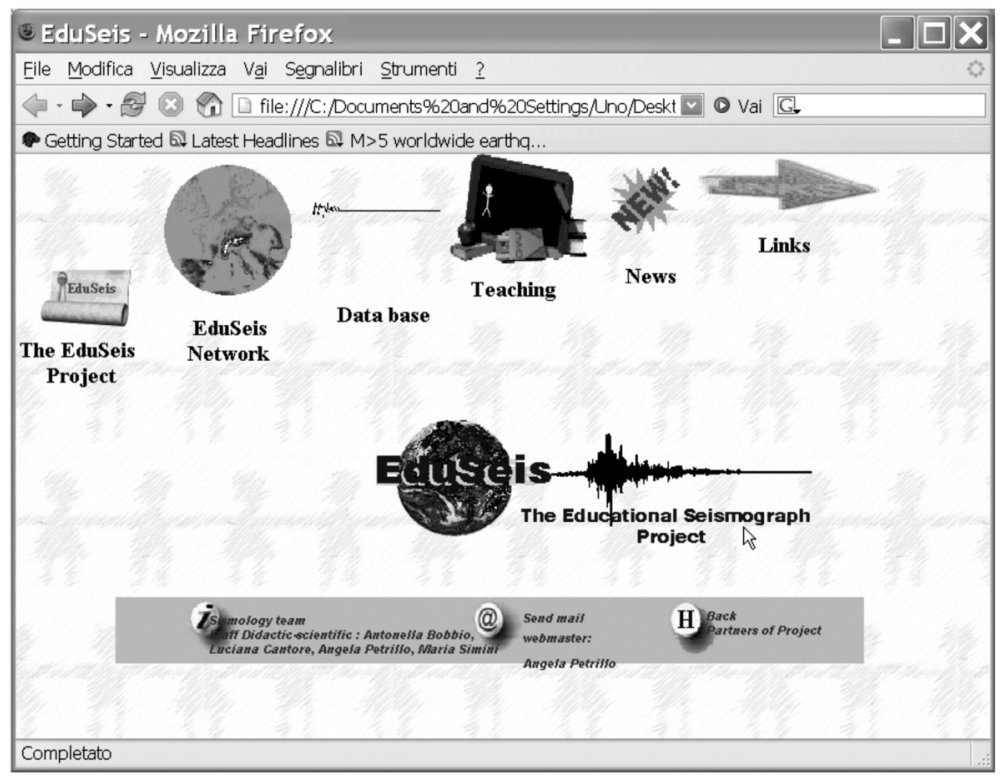

Fig. 1. The EduSeis website (http://eduseis.na.infn.it).

analysis and interpretation of seismological data. For this purpose, modules and teaching activities have been designed and tested using computer science and web-oriented tools (Cantore et al., 2005). The scientific objective is to introduce into high schools the use of advanced instruments and experimental methods that are usually restricted to research laboratories, with the main product being the creation of an earthquake waveform archive. Thus a large amount of this data can be used by the students and teachers for educational purposes. For the social objectives, the project represents an effective instrument for informing and creating an awareness of the seismic risk, for experimentation into the efficacy of scientific communication, and for an increase in the direct involvement of schools and the general public.

\section{The e-learning experiment in the ITIS «Majorana» technical high school}

E-learning has been defined as the use of new multimedia technologies and the potential of the internet to improve the quality of teaching/learning. According to this definition, rather than being a new tool for formal education that can be used in the classroom, e-learning should be considered as a modern method for teaching and learning that integrates and completes the work in classroom.

On the «ALPI» platform of the Edulab cultural association, an e-learning model has been built that is based on the EduSeis concepts and its related educational materials. This model is based on computer-supported collaborative learning (Ligorio, 1995; Trentin, 1998), which is an innovative method for teaching and learning that adopts modern information and communication technologies. The EduSeis educational activities (e.g., earthquake location and magnitude estimate, seismogram analysis) are mainly based on web and internet communication tools and are suitable for this kind of experimentation. Determination of their teaching value is also one of the main educational objectives of this project.

A number of students at the ITIS «Majorana» technical high school (Naples) who are following the teaching strategy of the «Learning 
Community» and the «Jigsaw» method (Clarke, 1994) have been involved in this cooperative elearning experiment. The basic idea is that the students work in small groups (communities) where each member evolves gradually from an initial stage as a «fellow learner». This is followed by an intermediate level as a «teacher», and then finally as a «scientist». The learning process is assisted and supervised by the teachers, who have already improved their use of the internet and their knowledge of Earth Science.

\subsection{The Jigsaw method at the Majorana school}

The Jigsaw method uses the cooperative concept to promote individual learning, whereby this kind of structure creates interdependence and status equalization (Clarke, 1994). This Jigsaw method is a very useful tool for helping students to integrate knowledge and understanding that has been drawn from various sources and experts. Indeed, the basic idea behind the Jigsaw method is very simple: a general theme and a number of related topics are identified, and the application of this strategy is carried through the following steps:

- define the general theme that the class will work on;

- split the class in small groups of students;

- assign to each group a topic related to the general theme. Each group member will become an expert in this topic, using didactic material and support from the teachers.

- Re-mix the students into new groups that include these experts of each topic;

- reassemble the original groups where each member teaches the rest of the group what they have learnt about the other topics;

- the groups each present their own analysis of the general theme to the entire class.

\subsection{Trial of the e-learning platform with the EduSeis tools}

Ten teachers from different disciplines and fifty students at different educational levels have been involved in the trials around this EduSeisbased e-learning platform. The fifty students were divided into five groups, so that students of different levels were present in each of these groups (Miranda, 2004). The general theme chosen for this experiment was seismology. This choice was prompted by the collaboration between the school and the research staff of the EduSeis project. Indeed, during this collaboration, teachers of scientific disciplines trained themselves on and experimented with the tools provided by the EduSeis website, which they evaluated as being suitable for this e-learning experiment. At the same time, to test the background knowledge of the students participating in the project, students were asked to initially complete a multiple-choice questionnaire on Seismology and Earth Sciences in general.

During the «kick-off» meeting, the teachers showed the «Edulab» platform architecture to all of the student groups and illustrated the guidelines for using the tools built on this platform (Edulab, 2001). One of each of the five didactic units concerning different topics on seismology that have been set-up on the EduSeis website were attributed to each group; these five units relate to the following:

- world-wide seismicity and earthquake genesis;

- seismometry and seismic networks;

- seismic waves and their propagation;

- earthquake classification according to epicentral distance;

- observation and interpretation of seismograms (complexity analysis).

In the first step, each group became the experts on their own topic. This was achieved by their using both the teaching material available from the EduSeis website, and advanced searching on the internet to improve their knowledge and to acquire further expertise on the subject (fig. 2). The exchange of data and information among the students within each group occurred through the internet, using the tools within the chat and forum services for document up-loading and down-loading, which were all made available through the platform. For each student the first approach is to consult and use the EduSeis material and tools available on the website, improving the knowledge on the topic through an internet research, the results of which have been shared with each member of its own group 
using the forum, the e-mail and the chat services. Most of student activity for the e-learning experiment was carried out via computer both in the school and at home, only a $30 \%$ of all experimentation phases were face-to-face with and without the teachers' presence.

In this phase, all of the students were considered as being apprentices (or «fellow learners»), and they were involved in:
- learning new concepts, and being opening to questioning their own knowledge;

- accessing new information using various internet communication channels;

- discussing their own ideas, doubts and problems, through the chat and forum services available through the platform.

As a major result of this phase, a number of documents (e.g., Powerpoint presentations, Word
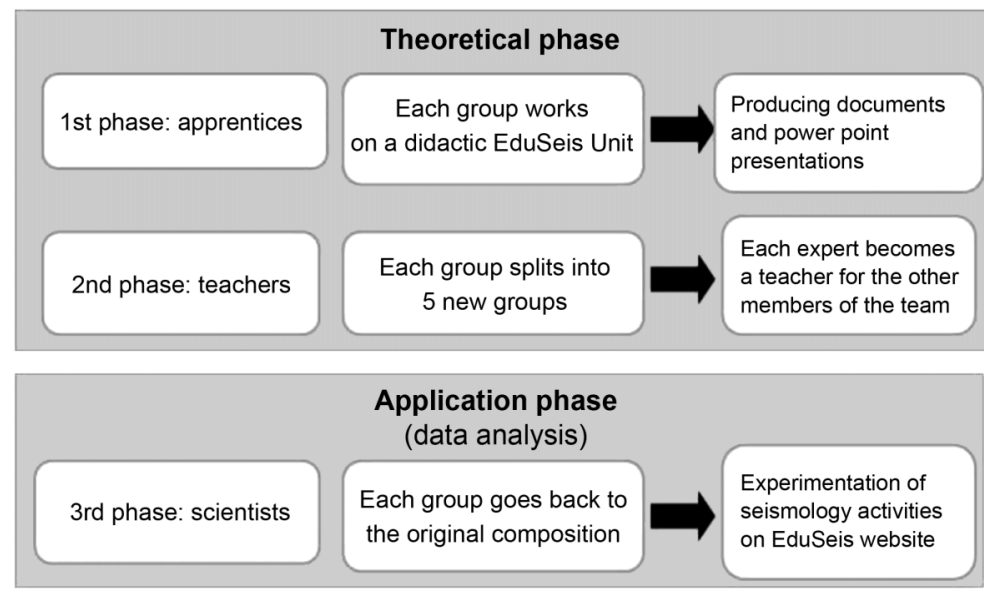

Fig. 2. A scheme of the e-learning experiment at the ITIS «Majorana» technical school, Naples.

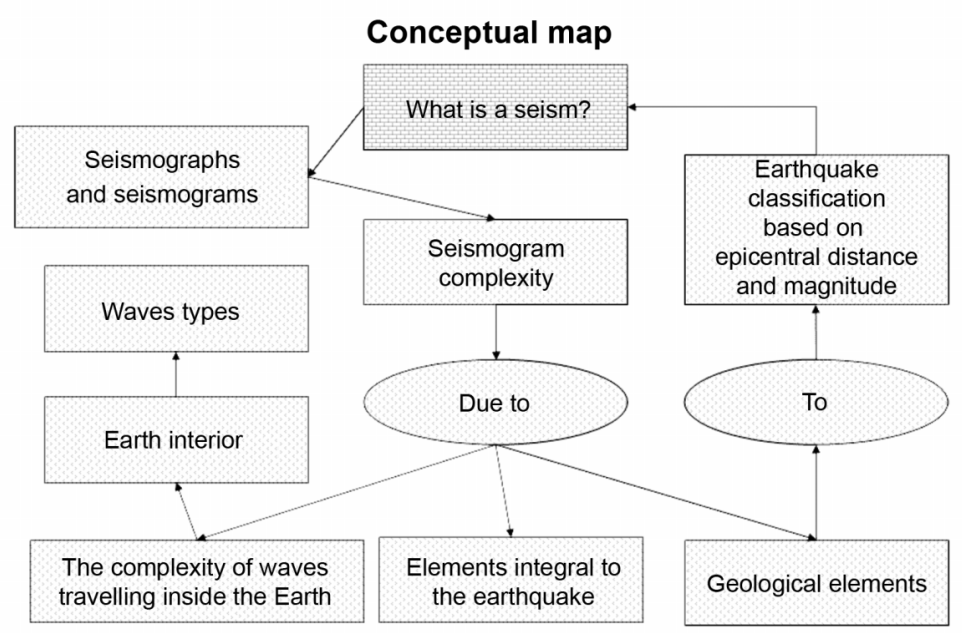

Fig. 3. An example of a typical product produced by the students in the 1 st phase of the process. The products are included on the website and made available for the community. 
documents, Excel data and analysis sheets) were produced by each group, and the high quality of the content demonstrated their enthusiastic participation and the success that they had obtained through working in these collaborative communities. A typical starting point for the realization of each product in the e-learning experiment is the generation of Conceptual maps which are diagrams showing the relationships between concepts in the form of propositions. Concepts are included within boxes whereas the relations between them are explicated by means of connecting lines. These maps can often be used to communicate complex ideas. An example of a Conceptual map produced by students is shown in fig. 3 .

In the second phase, each group was split, and five new groups were formed in such a way that an expert on each seismology topic covered (see above) was present in each new group, so that each student could then be a teacher for the other members of their new group. In this phase, all of the students were considered as «teachers», and this involved:

- sharing with each other of their own stock of knowledge;

- teaching of their acquired expertise to the other members of their new group;

- demonstrating the reasonableness of their own opinions to the other members of their new group.

In the last phase, the original five groups were re-assembled, and each member progressed further on the basis of the experience they had gained in the previous phases. Having acquired a deeper knowledge of these seismological topics, each group was ready to make full use of the EduSeis activities implemented on the website, by using either the web tools supplied or analogue devices in the school laboratories. At the end of the experiment, each group presented its work to the whole community, i.e. to the classes and the teachers involved in the experiment.

In this phase all of the students were considered as «scientists», and they were faced with the need to demonstrate:

- their acquisition of expertise within a new theme (i.e. seismology) that is not a part of the scholastic curricula;
- their ability to promote the diffusion of seismological concepts and an increased seismic risk awareness to a widespread community.

\section{The EduSeis didactic Unit: an example}

The teaching Unit chosen for showing the architecture of a typical didactic unit is: «Seismic waves and their propagation».

Four topics are correlated to this theme:

- Section 1: Seismic Wave Propagation.

- Section 2: The Interior of the Earth.

- Section 3: The Seismic Wave.

- Section 4: Travel-Time Curves.

Each section contains one or more activities that are designed around the use of web tools. In the following, the classical structure of an activity will be illustrated, with this example relating to the activity: «An analysis of the $P$ and $S$ waves on seismograms».

\subsection{Objectives}

Measurement of $P$-wave and $S$-wave first arrivals with the help of theoretical estimates from the Jeffreys and Bullen (1940) travel-time curves (these give the travel times of all of the main seismic phases from different depths of hypocentre to surface stations at different distances).

\subsection{Area of expertise: seismology}

The activity is subdivided into two main phases:

First phase - Inferring arrival times from Jeffreys and Bullen curves. Ingredients: an event selected from the EduSeis archives; the «distance applet» for the calculation of epicentral distance (fig. 4); Jeffreys and Bullen tables; a ruler.

Second phase - Estimation of $P$-wave and $S$-wave arrival times inferred from seismograms. Ingredients: an event selected from the EduSeis ar-chives; the «SeisGram2K applet» (Lomax, 2000) for the visualization and analysis of seismograms; the origin time of the earth- 


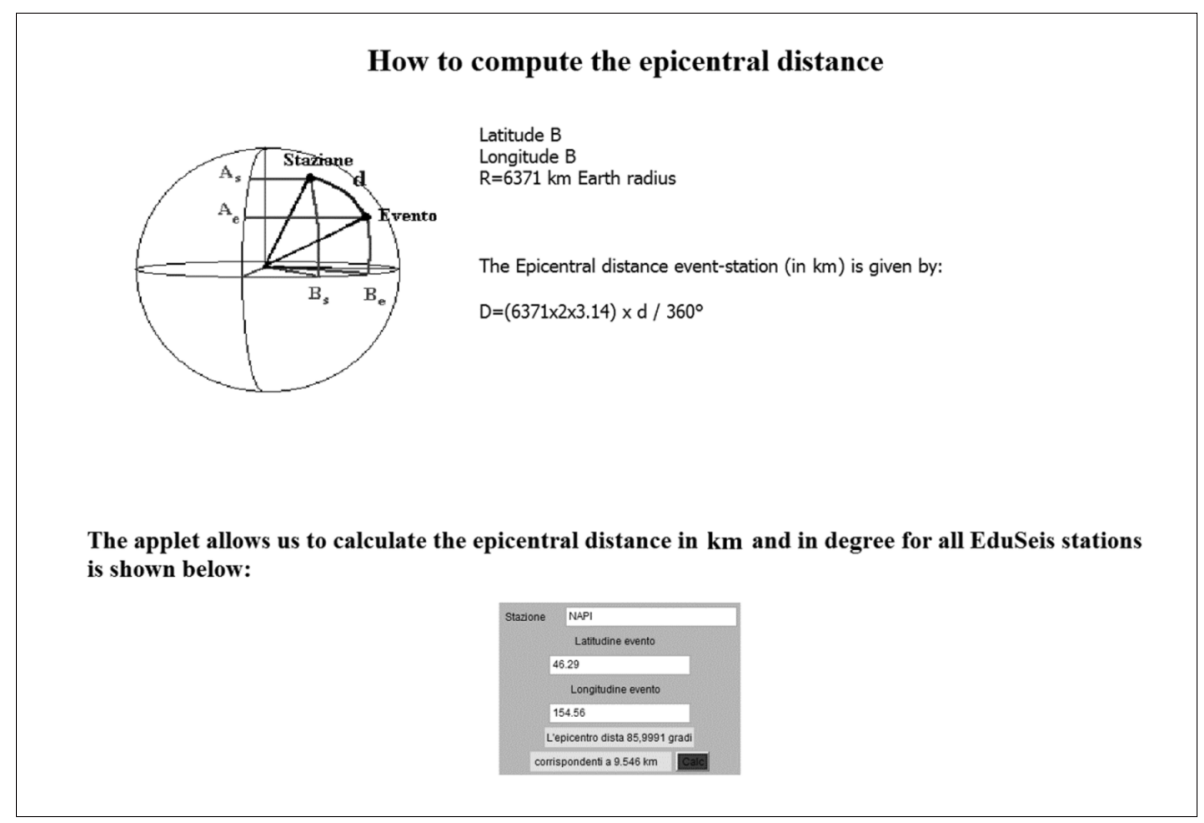

Fig. 4. A web tool for a didactic activity

quake inferred from national and/or international seismic alerting agencies; the theoretical values of the arrival times inferred from the Jeffreys and Bullen curves.

In this activity, the use of web tools under the supervision of the teachers allows the students to compute the epicentral distance (the distance from the earthquake epicentre to the point of observation) of the chosen event, and to recognize the first arrival of the $P$ and $S$ waves using the Jeffreys and Bullen curves to provide reference values. The basic idea of each of these activities is to lead the student through a «learning by discovering» process.

\section{Results and conclusions}

One of the most interesting factors that has arisen from this e-learning experiment has been to promote the working of the students and teachers within a «community of learners». In this model, the classroom is changed into a real community where everyone has different, but changing, roles, as apprentice, teacher and scientist, with the consequent exchange of tasks and responsibilities.

A selection of the products from this experiment have been published on the website of the school, and these have become a useful support for the didactic activities. The involvement of students in this high-social-impact activity represents an opportunity for the increasing of their own awareness of earthquake risk. This is thus seen as improving their understanding of seismic phenomena and the potential damage arising therefrom, along with their knowledge of the measures that can be implemented to mitigate these effects.

Figure 5a,b shows a comparison between the input and output values of a questionnaire administered at the beginning and the end of this e-learning experiment for two different age-level classes. Based on the number of correct answers, a quantitative value can be put on the knowledge that has been gained about the topic under consideration, and therefore the positive effects of this e-learning experiment. 
The evaluation of the results from this e-learning experiment has also provided useful insights into the contents and the didactic value of the EduSeis didactic modules and activities.

The success of this e-learning experiment is due to the great involvement and motivation of the students, who have provided a large number of high quality products that testify to their enthusiasm for working in cooperative communi- ties. The use of the network utilities for the elaboration of the final products has provided each student with the opportunity to feel that they are themselves a protagonist of the experimentation, and it has promoted the exchange of ideas and expertise between students and teachers. This innovative method that is based on the strategy of the «learning community» has, moreover, allowed a new approach to seismolo-

Questionnaire 1st-2nd levels: comparison between input and output values

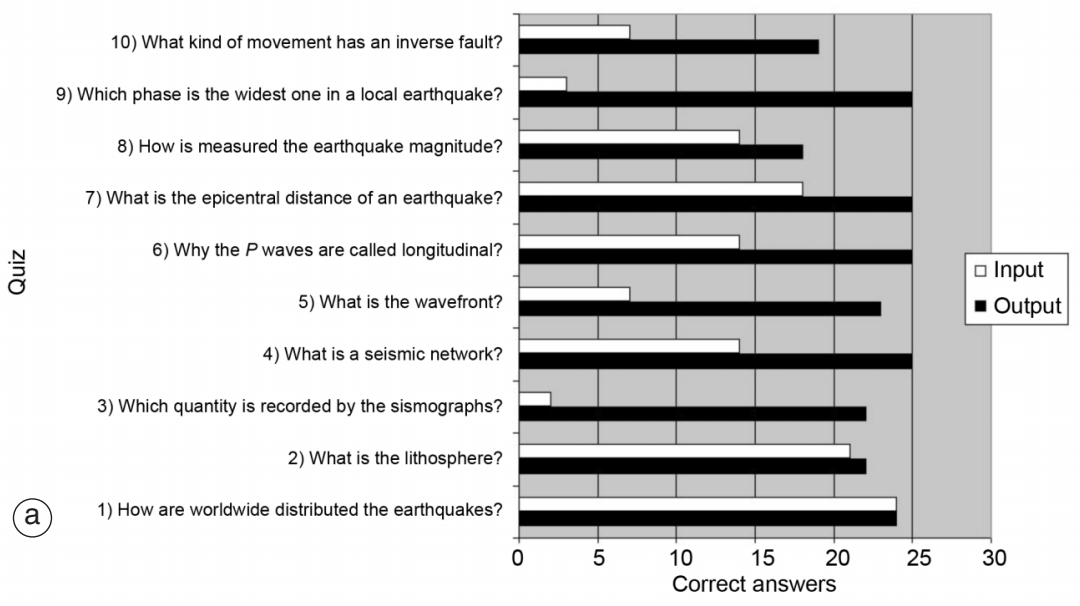

Questionnaire 3rd-4th levels: comparison between input and output values

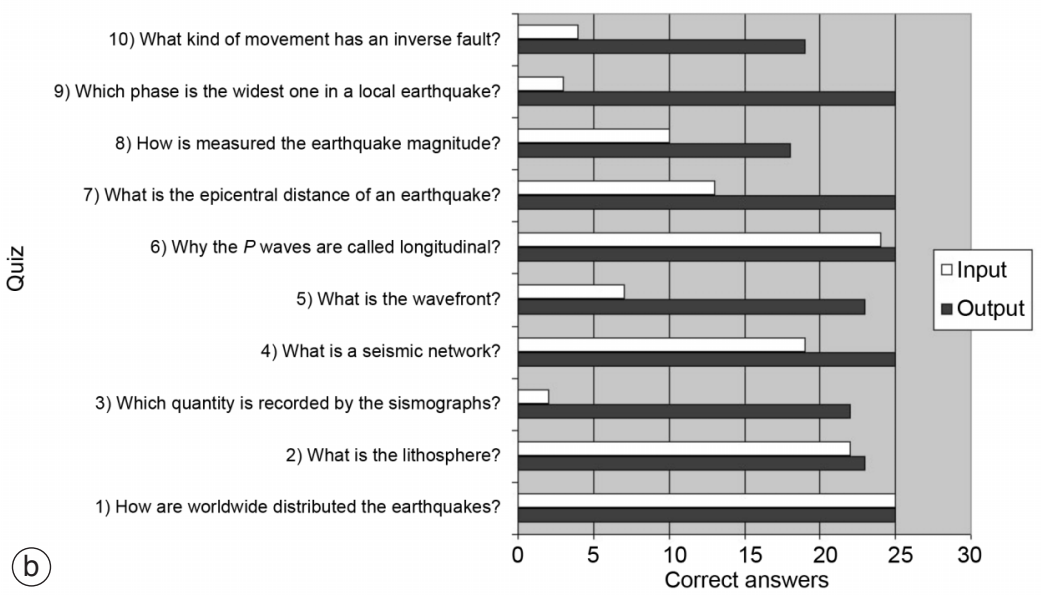

Fig. 5a,b. A comparison between before and after values of a questionaire administered at the beginning and the end of the experiment for 1st and 2nd leveles (a) and 3rd and 4th levels (b). 
gy through a multidisciplinary study, promoting the ability to deal with such complex themes as the study of seismology.

\section{Acknowledgements}

We are grateful to all of the teachers and students of the ITIS «Majorana» technical school in Naples who, with much enthusiasm, took on active roles in this project. We wish also to thank Angela Petrillo, Mariella Simini, André Herrero and Luca D'Auria for their contribution in the realization of EduSeis website. We acknowledge the anonymous referee for his fruitful comments and suggestions.

\section{REFERENCES}

BobBio, A. and A. Zollo (2000): The educational broadband seismic network at Naples (Southern Italy), Orfeus Newsletter, 2 (3), p. 23.

Cantore, L., A. Bobbio, F. di Martino, A. Petrillo, M. Simini and A. Zollo (2003): The EduSeis project in
Italy: a tool for training and awareness on the seismic risk, Seismol. Res. Lett., 74 (5), 596-602.

Cantore, L., A. Zollo, A. Bobbio, F. Di Martino and M. SiMINI (2005): Il Progetto EduSeis - Un Triennio di Esperienze Didattiche in Sismologia (CUEN, Napoli), pp. 50.

Clarke, J. (1994): Pieces of the puzzle: the Jigsaw method, in Handbook of Cooperative Learning Methods, edited by S. Sharan (Greenwood Press, Westport, CT), 34-50.

EDULAB (2001): Associazione Culturale per la Ricerca sulla Didattica Multimediale EDUcation LABoratory (http://www.edulab.it).

JefFreys, H. and K.E. Bullen (1940): Seismological Tables (British Association for the Advancement of Science, Gray Milne Trust, London), pp. 48.

LIGORIO, M.B. (1995): «Community of Learners»: strumenti e metodi per imparare collaborando, TD - Tecnologie Didattiche, 1 (4), 22-35.

Lomax, A. (2000): Seisgram2k: Seismogram Visualization Software for the Internet (Anthony Lomax Scientific Software Mouans-Sartoux, France).

Miranda, N. (2004): EduSeis con l'ambiente Alpi, e-learning: formazione, modelli, proposte, in Seminario di Studio Università degli Studi di Macerata, Facoltà di Scienze della Formazione, April 2004.

Trentin, G. (1998): Insegnare e Apprendere in Rete (Zanichelli, Bologna), pp. 263.

(received December 18, 2006; accepted February 15, 2007) 